\title{
RET Is Dispensable for Maintenance of Midbrain Dopaminergic Neurons in Adult Mice
}

\author{
Sanjay Jain, ${ }^{1}$ Judith P. Golden, ${ }^{2}$ David Wozniak, ${ }^{3}$ Elizabeth Pehek, ${ }^{5}$ Eugene M. Johnson Jr, ${ }^{2,4}$ and Jeffrey Milbrandt ${ }^{4}$ \\ ${ }^{1}$ Department of Medicine, Renal Division, and Departments of ${ }^{2}$ Molecular Biology and Pharmacology, ${ }^{3}$ Psychiatry, ${ }^{4}$ Pathology, and Neurology and HOPE \\ Center for Neurological Disorders, Washington University School of Medicine, St. Louis, Missouri 63110, and 5epartments of Psychiatry and \\ Neuroscience, Case Western Reserve University School of Medicine, Cleveland, Ohio 44106
}

Glial cell-line derived neurotrophic factor (GDNF)-mediated RET tyrosine kinase signaling is implicated in the survival of several PNS and CNS neuronal populations that are important in the pathogenesis of several disorders including Parkinson's disease and drug addiction. However, it has been difficult to study these processes and the physiological importance of this pathway in adult mice because of the neonatal lethality of Gdnf and Ret null mice. We report successful creation of RET conditional reporter mice to investigate postnatal physiologic roles of RET and monitor the fate of RET-expressing cell types. To delete RET specifically in dopaminergic neurons and determine the physiologic requirement of RET in the maintenance of substantia nigra compacta (SNC) and ventral tegmental area (VTA), we bred the RET conditional mice with mice that specifically express Cre from the dopamine transporter (Dat) locus. A detailed morphometric and biochemical analysis including dopaminergic neuron number and size in SNC and VTA, and fiber density in the striatum and nucleus accumbens, and dopamine levels indicate that RET is not required for providing global trophic support to midbrain dopaminergic neurons in adult mice. Furthermore, RET deficiency in these neurons does not cause major sensorimotor abnormalities. Hence our results support the idea that RET signaling is not critical for the normal physiology of the SNC and VTA in adult mice.

Key words: RET; GDNF; Parkinson; addiction; dopamine; RTK

\section{Introduction}

The midbrain dopamine system, composed of the nigrostriatal, mesolimbic, and mesocortical pathways, has been implicated in a variety of neurologic disorders, including Parkinson's disease (PD) and psychological drug addiction. The proper function of the nigrostriatal system depends on dopaminergic neurons located within the pars compacta of the substantia nigra (SNC) that project to nuclei within the striatum. The dopaminergic neurons of the mesolimbic system are located in an area medial to the SNC known as the ventral tegmental area (VTA) that primarily innervates the nucleus accumbens (NAc), a major center that plays a role in reward-related behaviors, euphoria, and addiction (Koob et al., 1998). Both PD and addiction are debilitating conditions accounting for significant morbidity and mortality.

One of the hallmarks of PD is the loss of dopaminergic neurons of the SNC. This results in dopamine depletion in the striatum and in sensorimotor abnormalities. Although dopamine replenishment is being used as a therapy for $\mathrm{PD}$, the majority of

Received May 3, 2006; revised Aug. 18, 2006; accepted Sept. 14, 2006.

This work was supported by HOPE Center for Neurological Disorders, National Institutes of Health Grants AG13730 and NS39358 (J.M.), AG13729 (E.M.J), and HD047396-01 (S.J.), and the Michael J. Fox Foundation (E.M.J.). We thank Kelli Simburger, Amber Nielson, Amy Strickland, Amanda Knoten, Patricia Osborne, Tatiana Gorodinsky, and Nina Panchenko for excellent technical assistance. We are grateful to Amelia Gallitano and Anneliese Schaefer for their help with brain dissections and neuroanatomy and to Hideki Enomoto for numerous discussions. We thank Xiaoxi Zhuang for the generous gift of DatCre animals.

Correspondence should be addressed to Sanjay Jain at the above address, E-mail: sjain22@wustl.edu; or Eugene

M. Johnson Jr, E-mail: eugene.johnson@wustl.edu; or Jeffery Milbrandt, E-mail: jeff@pathbox.wustl.edu.

DOI:10.1523/JNEUROSCI.1876-06.2006

Copyright $\odot 2006$ Society for Neuroscience ～0270-6474/06/2611230-09\$15.00/0 patients eventually become refractory to this treatment. Therefore, delineating molecular mechanisms that regulate survival of the SNC dopaminergic neurons may provide an avenue for better treatment or prevention of PD. To this end, numerous studies in vitro, in animal models that recapitulate $\mathrm{PD}$, and in human $\mathrm{PD}$ patients, have shown that glial cell-line derived neurotrophic factor (GDNF) family ligands (GFLs) promote increased survival of SNC dopaminergic neurons, reduce functional deficits caused by dopaminergic toxins, and improve parkinsonian symptoms (Gash et al., 1996; Cheng et al., 1998; Date et al., 1998; Horger et al., 1998; Kordower et al., 2000; Tomac et al., 2000; Sun et al., 2004; Jakobsen et al., 2005). GFL ligands (GDNF and Neurturin) have been, or are in clinical trials in the treatment of PD (Gill et al., 2003; Slevin et al., 2005). Furthermore, the GFLs also ameliorate addictive behavior to both narcotics and alcohol in rodents (Messer et al., 2000; Green-Sadan et al., 2003, 2005; He et al., 2005). Although the therapeutic potential of GFLs to treat diseases associated with abnormalities in the dopaminergic system is certainly appreciated, the precise physiological role of GFLs in these dopaminergic pathways is not well defined.

The GFLs [GDNF, NRTN (neurturin), ARTN (artemin), and PSPN (persephin)] form a complex with the GDNF family coreceptors (GFR $\alpha 1-4)$ and receptor tyrosine kinase RET to activate downstream intracellular signaling cascades such as PLC $\gamma$ (phospholipase $\mathrm{C} \gamma$ ), PI3K (phosphatidylinositol 3-kinase)/AKT, and MAPK (mitogen-activated protein kinase) (Baloh et al., 2000). The activation of these cascades results in modulating cell survival, proliferation, migration, and apoptosis. Therefore, one 
postulated hypothesis has been that GFL-mediated midbrain dopaminergic neuron survival requires RET activity. Although RET signaling is not required for the embryonic development of neurons in the SNC or VTA (Airaksinen et al., 1999; Jain et al., 2004), its direct role in their physiological maintenance or in the function of dopaminergic neurons in adulthood is not known. This is primarily the result of the neonatal lethality of Ret-, Gfro1-, and $G d n f$-deficient mice that precludes an analysis of the adult dopaminergic systems in these animals.

To circumvent this problem and delineate the physiologic role of RET in SNC and VTA function, we have specifically deleted RET in dopaminergic neurons by breeding mice harboring a conditional RET allele with mice that express dopaminergic neuron specific dopamine transporter-driven Cre recombinase (DatCre). Morphometric analyses of adult mice lacking RET specifically in the dopaminergic neurons show no overt abnormalities in the number or size of tyrosine hydroxylase (TH)-positive neurons in the SNC and VTA, or in innervation density at their targets compared with controls. The levels of dopamine and dopamine metabolites were also normal in these mutant mice. Consistent with the normal morphological and biochemical findings, mice with RET conditionally deleted from the dopaminergic neurons did not exhibit significant sensorimotor abnormalities except for a modest reduction in locomotor activity. Thus, our results provide evidence that RET signaling in dopaminergic neurons does not play a significant role in providing global trophic support to neurons in the SNC and VTA in adult mice.

\section{Materials and Methods}

Animal generation. Institution-approved protocols were followed for all animal studies. To generate the RET conditional animals, we engineered a targeting construct that could be homologously recombined into the first coding exon of the Ret locus in an identical manner to the strategy we previously used to generate a number of Ret-knock-in mice (Enomoto et al., 2001; Jain et al., 2004, 2006). The targeting construct contained the human RET9 cDNA-SV40intronpolyA signal flanked by loxP sites (RETflox) followed by enhanced green fluorescent protein (EGFP) reporter and a neomycin resistance marker (neo) that was flanked by flp recombinase sites (FRT) (RETfloxEGFPfrt-neo-frt) (see Fig. 1A). For homologous recombination, we used 129Sv-derived R1 ES cells and the recombined allele was identified by Southern blotting (Jain et al., 2004). Male chimeric mice were bred to transgenic mice expressing FLP recombinase to delete neo and the resultant mice harboring the RET conditional allele (RETfloxEGFP) were further propagated and used for experiments on a mixed genetic background (129/SvJ:C57BL/6). Routine genotyping to detect the wild-type or knocked-in RETfloxEGFP allele was performed using PCR (Jain et al., 2004). Deletion of neo was confirmed with the forward primer P6334 (5'-CTCGGCATGGACGAGCTGTACAAG-3') and the reverse primer P4828 (Jain et al., 2004). Mice harboring the RETfloxEGFP allele were bred with $\beta$-actinCre mice (Meyers et al., 1998) and the progeny were genotyped by PCR with the forward primer P6855 (Jain et al., 2004) and reverse primer P8428 (5'-GCCGTTTACGTCGCCGTCCAGCTCGACCAG-3') to ensure successful conditional deletion of RET in vivo.

Tissue preparation and immunohistochemistry. Animals were anesthetized, killed by cervical dislocation, and perfused with $4 \%$ paraformaldehyde, and the fixed tissues were either paraffin embedded or cryoprotected with $30 \%$ sucrose for immunohistochemical studies (Jain et al., 2004; Naughton et al., 2006). Unfixed whole embryos or fixed tissues were used to visualize EGFP in $\operatorname{Ret}^{\text {RETfloxEGFP/+ }}: \beta$-actinCre mice to confirm successful RET deletion and validate the accuracy of EGFP expression in known RET-expressing cell types. Coronal brain cryosections (40 $\mu \mathrm{m})$ from adult mice (6-12 months of age) were used for EGFP detection, tyrosine hydroxylase (TH) (Jain et al., 2004), or RET immunohistochemistry (Naughton et al., 2006) in quantitative and morphometric studies (see below). The microscopic analysis used for EGFP detection in whole embryos or tissues and for immunofluorescence have been described previously (Jain et al., 2006). MetaMorph software was used to capture the images using the deconvolution option, and Adobe Photoshop CS and Corel Draw software were used for preparation of figures.

Quantitative analyses of TH-positive neurons and fibers. Coronal brain sections $(40 \mu \mathrm{m})$ were cut in series through the entire SNC and VTA. Immunohistochemistry with anti- $\mathrm{TH}$ antibodies was performed on freefloating sections to determine differences in dopaminergic neuron numbers, somal areas, or fiber density in mice expressing RET (at least one Ret "+" allele present) or without RET (Ret deleted in dopaminergic neurons). Deletion of RET in these neurons was also confirmed with antiRET antibodies and direct visualization of EGFP signal. For cell number, TH-positive neurons were counted in four sections (200 $\mu \mathrm{m}$ intervals) from SNC and VTA corresponding to plates 56, 58, 60, and 62 in the mouse brain atlas ( $n=4$ animals of each genotype) (Franklin and Paxinos, 1997). From each coronal section, all TH-positive cells in the SNC and VTA were counted. Somal areas of SNC and VTA dopaminergic neurons were determined from $>100$ randomly selected TH-positive neurons across the SNC (three different SNC regions: lateral, middle, and medial; 12 different areas per mouse) and VTA (two VTA regions: central region of left and right VTA; eight different areas per mouse) per anima ( $n=4$ animals of each genotype) using the NIH Image analysis software (ImageJ, version 1.62). Nuclear areas of TH-positive neurons from the SNC and VTA were also determined from the same sections as above. To determine differences in fiber density in the target regions of the SNC and VTA, the striatum, and the NAc, respectively, the area occupied by THpositive fibers was determined in coronal sections through the striatum (plates 19, 25, 34) and the NAc (plates 19, 22, 25) in a manner reported previously (Gundersen et al., 1988a,b; von Bohlen und Halbach et al., 2005). To this end, images of striatum (single region from three different sections) and NAc (two different regions including core and shell regions, from three different sections) from each animal were accessed using ImageJ software, and a $10 \times 10$ grid (100 grid marks) was used to determine the percent area occupied by $\mathrm{TH}$-positive fibers by counting the number of grid marks overlying a fiber (four random areas were used from each region). For example, if TH-positive fibers crossed 50 grid marks, the percent area occupied was represented as 50\%. For all quantitative studies, similar brain regions were sampled in each mouse. SigmaPlot software (SPSS) was used to determine statistical significance using the Student's $t$ test (type I error, <0.05) between the means of the indicated parameters in the control and the conditionally deleted RET mice.

Tissue preparation and determination of dopamine and metabolite levels. Levels of dopamine and its metabolites [homovanillic acid (HVA); 3,4dihydroxyphenylacetic acid (DOPAC)] were determined from striatum using HPLC (Pehek et al., 1992). Briefly, animals were killed by cervical dislocation; the brains were rapidly removed, frozen on dry ice, and sliced on a precooled $1 \mathrm{~mm}$ mouse brain matrix (Plastics One, Roanoke, VA) with razor blades. These slices were kept on ice, and the striatum was dissected according to the mouse brain atlas (plates 24-33) (Franklin and Paxinos, 1997). The sections were kept frozen until ready for analysis as previously described.

Behavior studies. Two groups of mice, one with the conditional deletion of RET in dopaminergic neurons (RET deleted), and the other harboring at least one Ret wild-type allele (RET present) were evaluated on the tests described below. The genetic dosage of the dopamine transporter Dat was equivalent in all mice. The persons conducting the behavioral tests were "blinded" with regard to the genotypes of the mice for all measures.

One hour test of locomotor activity/open-field behavior. This procedure (Wozniak et al., 2004) involved measuring activity in transparent (47.6 $\times$ $25.4 \times 20.6 \mathrm{~cm}$ high) polystyrene cages in which each cage was surrounded by a frame containing a $4 \times 8$ matrix of photocell pairs, the output of which was fed to an on-line computer (MotorMonitor; Hamilton-Kinder, Poway, CA). The system software (Hamilton-Kinder) was used to define a $33 \times 11 \mathrm{~cm}$ central zone and a peripheral or surrounding zone that was $5.5 \mathrm{~cm}$ wide with the sides of the cage being the outermost boundary. Dependent variables included the total number of ambulations and rearings, as well as the number of entries, the time 
spent, and the distance traveled in the center area and the time spent and distance traveled in the periphery surrounding the center.

Sensorimotor battery. Tests in the sensorimotor battery are used to evaluate balance, strength, and coordination as well as initiation and speed of movement. These tests are sensitive for detecting sensorimotor disturbances (Wang et al., 2002; Grady et al., 2006; Griffey et al., 2006). The battery (Wozniak et al., 2004) includes the following: inclined (60 and $90^{\circ}$ ) and inverted screen tests for measuring strength, and coordination; the platform and ledge tests for assessing balance and agility, walking initiation for evaluating initiation of movement, and pole test for measuring speed of movement during a complex motor task (e.g., bradykinesia).

Rotarod. To evaluate continuous motor coordination and balance the rotarod (Rotamex-5; Columbus Instruments, Columbus, $\mathrm{OH}$ ) test was performed under three different conditions: a stationary rod (60 s maximum), a rotating rod with a constant speed ( $5 \mathrm{rpm}$ for $60 \mathrm{~s}$ maximum), and a rod with an accelerating rotational speed (5-20 rpm over $0-180 \mathrm{~s}$ ) (Griffey et al., 2006). The protocol included three training sessions, each session being separated by $4 \mathrm{~d}$, in which each session included one trial on the stationary rod, two trials on the constant speed rotarod, and two trials on the "accelerating" rotarod. Time spent on the rod in each condition was used as the dependent variable. This protocol minimized motor learning to enhance test sensitivity.

Statistical analyses. ANOVA models typically containing two betweensubjects variables (genotype and gender) and sometimes one withinsubjects (repeated-measures) variable (e.g., trials) were used to analyze the behavioral data. The Huynh-Feldt adjustment of $\alpha$ levels was used for all within-subjects effects containing more than two levels to protect against violations of sphericity/compound symmetry assumptions. Bonferroni-corrected $p$ values were used when multiple comparisons were conducted.

\section{Results}

Strategy to generate RET conditional mice

The postnatal physiological roles of GDNF-mediated RET signaling are mostly unknown because of neonatal lethality of RETdeficient mice (Schuchardt et al., 1994, 1996; Enomoto et al., 2001). To overcome this obstacle, we engineered a "floxed" RET allele that could be conditionally deleted in those cell types that express the Cre recombinase (Fig. 1). To monitor cells that conditionally lose RET, we cloned the EGFP reporter downstream of the floxed RET allele. In this strategy, EGFP is only expressed when the floxed RET allele is deleted. Using homologous recombination, we successfully targeted the floxed RET-EGFP conditional allele into exon 1 of mouse Ret locus using a knockout-knock-in strategy we have previously used to study several RET-mutant forms (Enomoto et al., 2001; Jain et al., 2004, 2006) (see Materials and Methods). The conditionally targeted RET allele will be designated as RETfloxEGFP, and the presence of Cre denotes deletion of RET in the cell type expressing Cre. The homozygous RET conditional mice Ret RETfloxEGFP/RETfloxEGFP and hemizygous $\operatorname{Ret}^{\text {RETfloxEGFP/- }}$ were viable through adulthood and had no gross abnormalities ( $>1$ year) supporting the assumption that human conditional RET can support normal development.

To ensure proper functioning of the conditional RET allele in vivo (i.e., excision of RET and expression of EGFP), mice expressing the RETfloxEGFP allele were bred with $\beta$-actinCre mice. Robust expression of the EGFP reporter was detected in organs previously known to express RET during embryogenesis and in the postnatal period (e.g., kidneys, enteric nervous system, testis, DRGs, and spinal motor neurons) including the midbrain dopaminergic neurons of the SNC and the VTA in the resultant $\operatorname{Ret}^{\text {RETfloxEGFP/+ }}: \beta$-actinCre mice (Fig. 1) (data not shown). We also confirmed that complete deletion of the conditional allele by Cre $\left(\operatorname{Ret}^{\text {RETfloxEGFP/RETfloxEGFP }}: \beta\right.$-actinCre) in mice results in a phenotype identical to the previously reported conventional Ret-
A

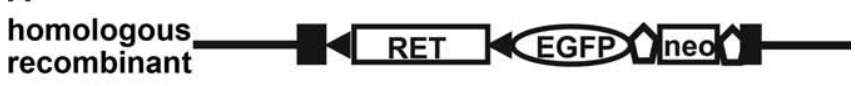

JFIp recombination

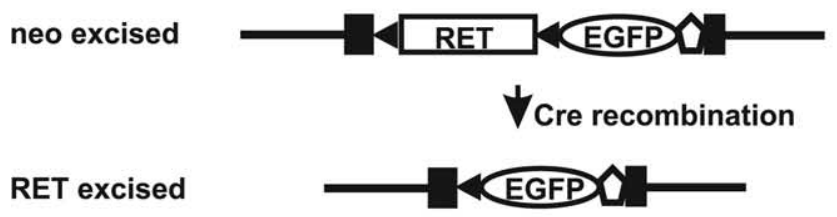

B
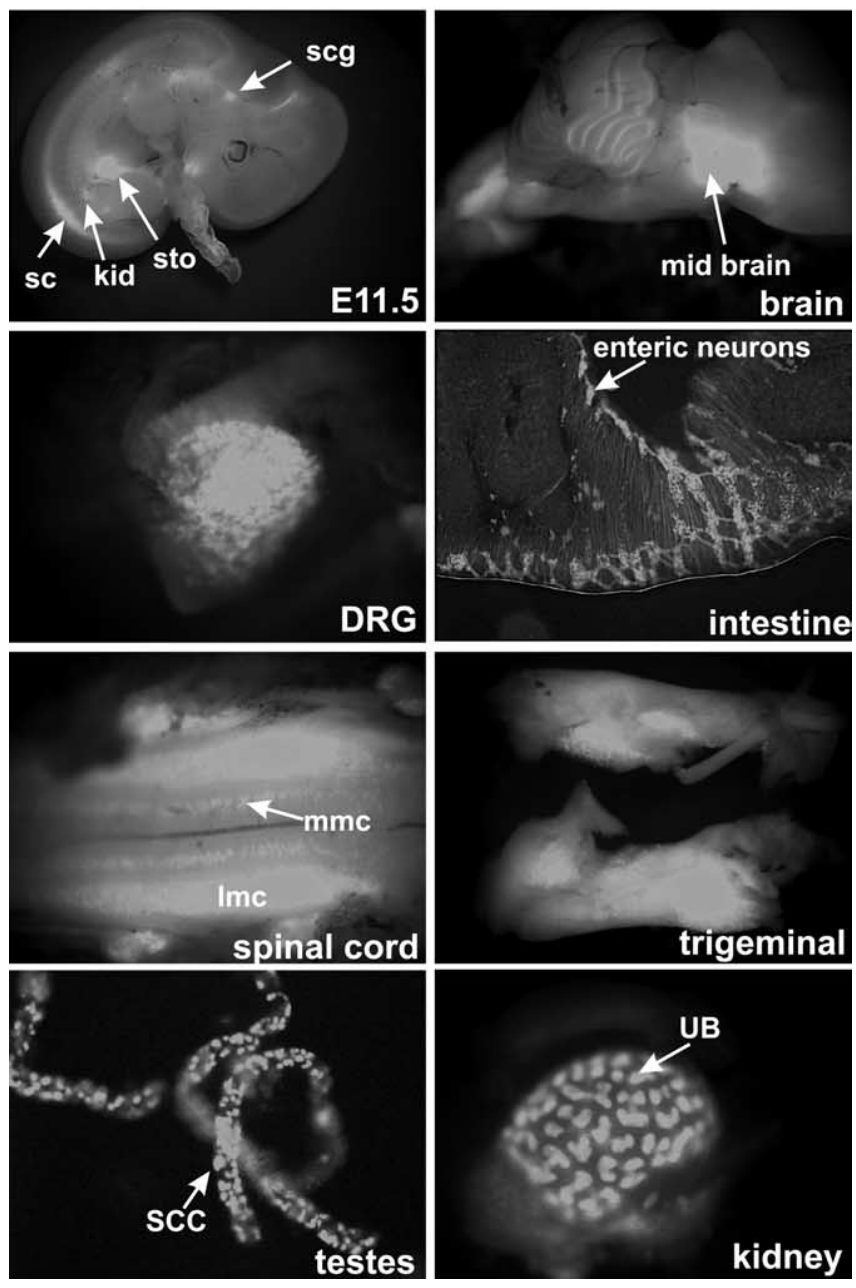

Figure 1. Generation of RET conditional reporter mice. $\boldsymbol{A}$, Schematic depicting the targeting construct used for homologous recombination into exon 1 (black box) of the mouse Ret locus (black line) to generate the RET conditional mice. The homologously recombined construct harbors the floxed (black triangles, loxP sites) wild-type human RET cDNA, EGFP reporter (oval) and neo resistance marker flanked by the Flp recombination sites (open pentagons, frt). The different steps to obtain RET excision by breeding the RET conditional animals to appropriate Cre-expressing animals are indicated. $\boldsymbol{B}$, Conditional deletion of RET CDNA results in EGFP expression from Ret locus at sites of RET-expression. In $\operatorname{Ret}^{\text {RETfloxEGFP/+ }}: \beta$-actinCre mice, EGFP signal was directly visualized in embryo [embryonic day 11.5 (E11.5)] (scg, superior cervical ganglion; sto, stomach; kid, kidney; sc, spinal cord) or the indicated regions of various tissues [DRG, postnatal day 7 (P7) dorsal root ganglion; Imc, P7 lateral motor column; mmc, P7 medial motor column; scc, P7 spermatogonial stem cells; UB, E13.5 branching ureteric buds]. 
null animals (renal agenesis, intestinal aganglionosis, and normally developed midbrain dopaminergic neurons) at birth (supplemental Fig. 1, available at www.jneurosci.org as supplemental material) (data not shown) (Schuchardt et al., 1994; Enomoto et al., 2001). These experiments confirmed successful RET excision and subsequent EGFP expression in mice harboring the conditional RETfloxEGFP allele, and hence confirming the usefulness of this conditional mouse to study postnatal roles of RET signaling (see below).

\section{Specific and efficient excision of conditional RET allele in midbrain dopaminergic neurons mediated by Cre expressed from Dat locus}

Tissue-specific conditional deletion of genes is a powerful approach for studying postnatal function of genes whose loss during embryogenesis is lethal. Mice expressing Cre from the dopamine transporter locus ( $\mathrm{Dat}^{\mathrm{Cre} /+}$ ) exhibit highly efficient embryonic Cre-mediated reporter expression (>90\%) in the dopaminergic neurons of the SNC and VTA (Zhuang et al., 2005). We therefore reasoned that crossing RET conditional mice to the DatCre mice would allow us to specifically delete RET in the dopaminergic neurons of the SNC and VTA, thus enabling us to determine whether RET-mediated signaling is critical for the maintenance of these neurons. We performed a series of experiments to first determine whether Cre expressed from the Dat locus catalyzes efficient and specific deletion of RET from the SNC and VTA dopaminergic neurons in RET conditional mice.

For these studies, we generated compound hemizygous mice that express one conditional RET allele and one Cre allele $\left(\right.$ Ret $^{\text {RETfloxEGFP/+ }}$ :Dat ${ }^{\mathrm{Cre} /+}$; the "+" denotes the endogenous wild-type mouse allele). The advantage of using a hemizygous RET conditional allele in these initial characterization studies is that it allows simultaneous identification of cells in which RET has been deleted as indicated by the EGFP reporter and evaluation of the overlap with the endogenous RET-expressing cell population (from the "+" allele) as determined by RET immunohistochemistry (see below), thereby allowing assessment of both specificity and extent of RET excision in dopaminergic neurons.

We first determined that RET can be excised by DatCre in Ret $^{\text {RETfloxEGFP/+ }}: \mathrm{Dat}^{\mathrm{Cre} /+}$ mice by monitoring EGFP expression. Robust EGFP signal was visualized in both the SNC and the VTA, indicating that Cre expressed from the Dat locus can successfully delete at least a single RET conditional allele in the SNC and the VTA (Fig. 2A). Results of immunohistochemistry with anti-RET or anti-TH antibodies and direct visualization of EGFP signal in $\operatorname{Ret}^{\text {RETfloxEGFP/+}}:$ Dat ${ }^{\mathrm{Cre} /+}$ mice demonstrate virtually complete overlap between cells expressing EGFP (indicating deletion of conditional RET allele) and Ret-positive (representing the endogenous mouse wild-type allele) cells in both the SNC and the VTA neurons (Fig. 2B) (data not shown). We also examined the timing of DatCre-mediated recombination at the Ret locus. We found that DatCre excises the RET conditional allele in virtually all dopaminergic neurons by birth, before the naturally occurring cell death occurs (supplemental Fig. 2, available at www.jneurosci. org as supplemental material). These results further demonstrated that Cre expressed from the Dat locus is highly efficient in excising RET, consistent with the efficiency of this approach for other alleles (Zhuang et al., 2005).

We next used RET immunohistochemistry and EGFP visualization to determine the specificity of RET deletion by DatCre in various RET-expressing CNS neurons. Results demonstrate that, in Ret $^{\text {RETfloxEGFP/+ }}:$ Dat ${ }^{\text {Cre } /+}$ mice, EGFP was readily detected in the dopaminergic neurons of the SNC and VTA (A9, A10 cell
A

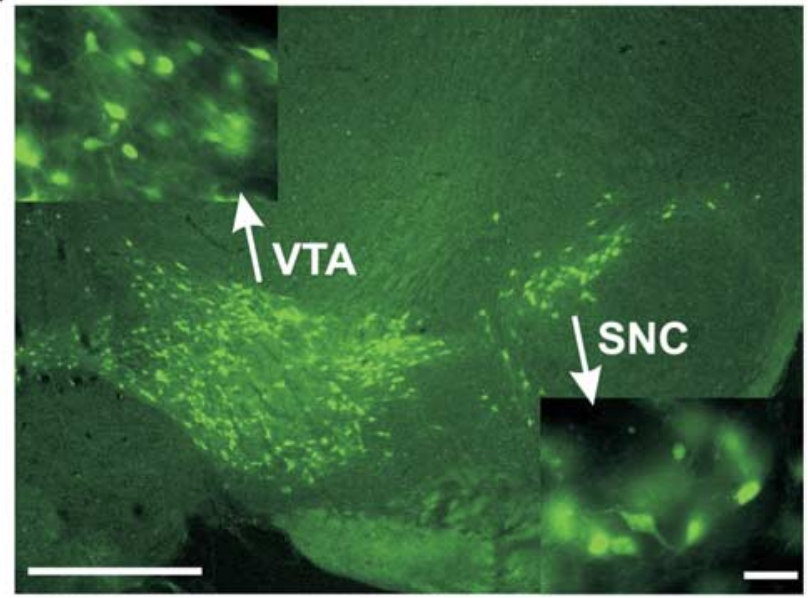

B
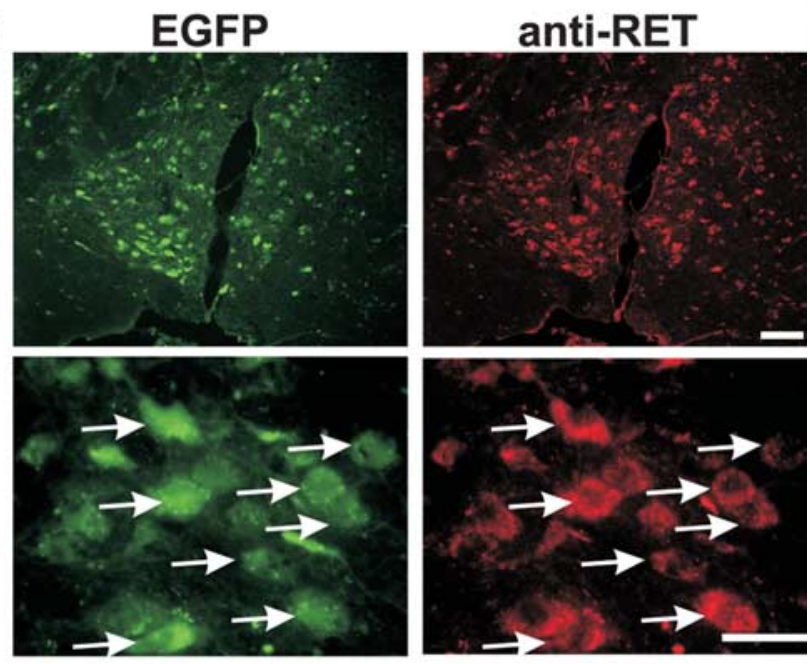

C
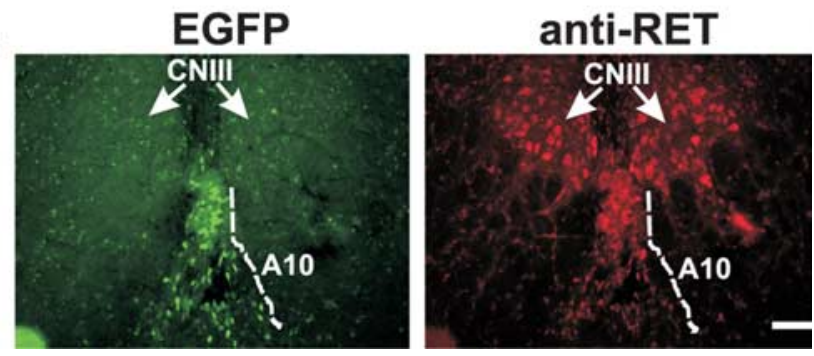

Figure 2. Characterization of DatCre-mediated RET excision in the midbrain dopaminergic neurons. $\boldsymbol{A}$, EGFP detection in whole-mount midbrain coronal sections through the A9 (SNC) and A10 (VTA) dopaminergic neurons. The intense green fluorescence in the VTA and SNC neurons (inset, high magnification) represents successful deletion of the conditional RET allele in Ret $^{\text {RETfloxEGFP/+ }}$ :Dat ${ }^{\text {Cre/+ }}$ mice. $B$, Immunohistochemistry with anti-RET antibodies (red) and direct EGFP visualization (green) on VTA dopaminergic neurons in $\operatorname{Ret}^{\text {RETfloxEGFP/+ }}$ :Dat ${ }^{\text {(re/+ }}$ mice. Note near complete overlap (arrows) of EGFP signal (represents the conditionally deleted RET allele) and RET (endogenous wild-type "+ " Ret allele) in the VTA indicates efficient excision of RET by DatCre (top, low magnification; bottom, high magnification). C, Among the RETexpressing cell types in the brain (dopaminergic and nondopaminergic), DatCre-mediated RET excision occurs specifically in the RET-positive dopaminergic neurons (green EGFP and red anti-RET signal in the $\mathrm{A} 10$ group shown here) and not in the RET-positive nondopaminergic CNIII neurons (absence of EGFP detection but presence of red anti-RET signal) in $\operatorname{Ret}^{\text {RETfloxEGFP/+ }}:$ Dat ${ }^{\text {(re)+ }}$ mice. Scale bars: $\boldsymbol{A}, 500 \mu \mathrm{m}$; inset, $50 \mu \mathrm{m} ; \boldsymbol{B}$, top, $100 \mu \mathrm{m}$; bottom, $25 \mu \mathrm{m} ; C, 100 \mu \mathrm{m}$. 


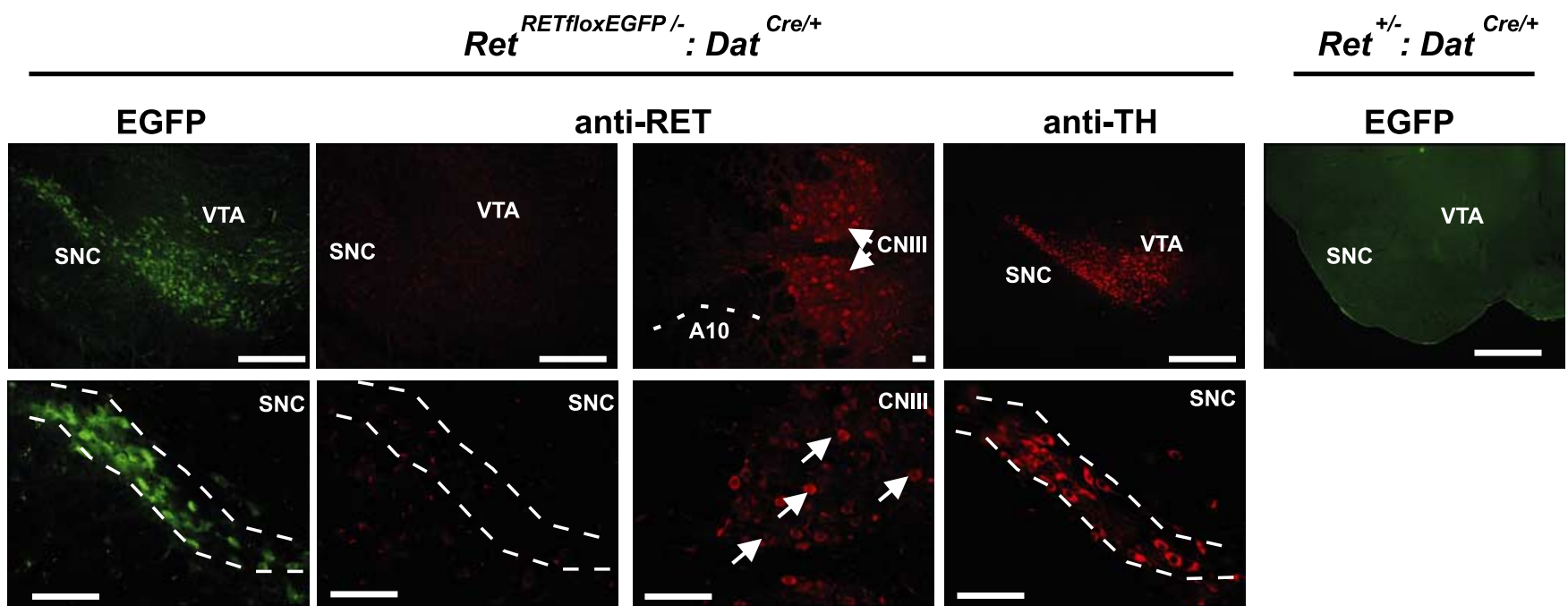

Figure 3. RET is successfully deleted in virtually all midbrain dopaminergic neurons. Direct EGFP detection or anti-RET, or anti-TH immunohistochemistry at low (top) and high power (bottom) of the indicated midbrain regions of Ret ${ }^{\text {REFfoxEGFP/- }}$ :Dat ${ }^{\text {re/ }+}$ mice shows robust EGFP expression indicating successful deletion of RET from virtually all dopaminergic neurons (EGFP will only be expressed when the RET floxed cDNA is deleted; the " - " represents Ret null allele; thus only the conditional allele needs to be deleted to obtain complete excision of RET from dopaminergic neurons). RET-immunopositive cells were not detected in SNC or VTA in the same midbrain section that show EGFP signal, indicating RET deletion from these neurons. As a control, RET-positive cells were detected in the nondopaminergic CNIII neurons in Ret ${ }^{\text {REFfloxEGFP/- }}$ :Dat ${ }^{\text {Cre/+ }}$ mice demonstrating that absent RET immunopositivity in the SNC and VTA was not attributable to diminished sensitivity of RET immunohistochemistry. Anti-TH immunohistochemistry on adjacent sections confirmed presence of dopaminergic neurons in Ret ${ }^{\text {REFfloxEGFP/- }}$ :Dat ${ }^{\text {Cre/+ }}$ mice. Also, note that EGFP is not detected in the midbrain in mice that do not harbor the RET conditional reporter allele (Ret ${ }^{+/-}:$Dat ${ }^{\text {(re/+ }}$ mice). Scale bars: top, $500 \mu \mathrm{m}$; bottom, $100 \mu \mathrm{m}$.

groups), but not in nondopaminergic RET-positive cell types such as red nucleus, CNIII nucleus, and locus ceruleus (Fig. 2C) (data not shown), indicating that DatCre-mediated RET deletion in dopaminergic neurons is highly specific. The above characterization studies established that RET can be conditionally deleted specifically and with very high efficiency in midbrain dopaminergic neurons of both the SNC and VTA in mice that express both the RET conditional and the DatCre alleles.

Finally, we generated adult animals (8-12 months of age) that express one Ret null allele ("-") and one conditional RET allele (dopaminergic conditional null animals) on the background of $\mathrm{Dat} \mathrm{Cre} /+^{+}$mice to enable complete deletion of RET in dopaminergic neurons ( $\operatorname{Ret}^{\text {RETfloxEGFP/- }^{-} \text {Dat }}{ }^{\mathrm{Cre} /+}$ ). In these conditional null animals, visualization of the EGFP reporter indicates complete absence of RET. EGFP signal is readily visualized in the dopaminergic neurons of adult Ret ${ }^{\text {RETfloxEGFP/- }}:$ Dat ${ }^{\text {Cre/+ }}$ mice, whereas RET is not detected in these neurons, thus demonstrating successful elimination of RET from the midbrain dopaminergic neurons (Fig. 3) (data not shown). Immunohistochemistry with anti-TH antibodies in these mice confirms the presence of dopaminergic neurons despite absence of RET. RET-expressing cells were detected in nondopaminergic cells, confirming the specific RET deletion only in the midbrain dopaminergic neurons as mentioned above. These results demonstrate that viable $\operatorname{Ret}^{\text {RETfloxEGFP/- }}:$ Dat ${ }^{\mathrm{Cre} /+}$ mice were successfully generated to determine the physiological importance of RET in midbrain dopaminergic neurons (see below).

\section{Morphometric analysis of midbrain dopaminergic neurons in} RET conditional animals

Because known physiological effects of GFLs occur through RET, and because GFLs provide trophic support to dopaminergic neurons under stress, we next examined whether RET is physiologically required to provide trophic support for midbrain dopaminergic neurons in adult mice (8-12 months of age). To examine this hypothesis, we performed detailed morphological characterization of SNC and VTA dopaminergic neurons in $\operatorname{Ret}^{\text {RETfloxEGFP/- }}$ :
Dat ${ }^{\text {Cre/+ }}$ mice. We used TH immunohistochemistry to specifically quantify abnormalities in TH-positive neuron number and somal area in SNC and VTA, and fiber density in striatum and NAc, key target areas of SNC and VTA, respectively, compared with control mice harboring at least one wild-type RET allele on $\mathrm{Dat}^{\mathrm{Cre} /+}$ background (e.g., Ret ${ }^{+/+}: \mathrm{Dat}^{\mathrm{Cre} /+}$ or $\mathrm{Ret}^{+/-}$:Dat ${ }^{\mathrm{Cre} /+}$ or Ret $\mathrm{RETfloxEGFP/+}^{\text {: }}$ $\mathrm{Dat}^{\mathrm{Cre} /+}$ mice). Abnormalities in these parameters are typically seen in PD animal models and would indicate that RET is physiologically important in providing global trophic support to midbrain dopaminergic neurons.

We found that total cell counts of dopaminergic neurons determined from sections that encompass the entire SNC and VTA were similar in both the Ret ${ }^{\text {RETfloxEGFP/- }}: \mathrm{Dat}^{\mathrm{Cre} /+}$ (RET absent) and the control mice (RET present), indicating that RET is not essential for development or survival of these neurons (Fig. 4A). We also examined neuronal size because a decreased somal area despite normal cell number has been observed in other neuronal populations in which GFL-RET signaling is required for survival and maintenance (Gianino et al., 2003; Jain et al., 2004). However, loss of RET in Ret ${ }^{\text {RETfloxEGFP/- }}:$ Dat ${ }^{\text {Cre/+ }}$ mice did not significantly affect the somal area of neurons in the SNC or the VTA, again suggesting that RET is not required under normal physiological circumstances to provide trophic support to these neurons (Fig. $4 B$ ). We also did not find any difference between the nuclear areas of the TH-positive neurons (mean \pm SEM) of the control VTA (561 \pm 39$)$ and RET-absent VTA (603 \pm 47$)$, and that of control SNC (607 \pm 51$)$ and RET-absent SNC (660 \pm 52$)$ mice.

In other systems, RET deficiency results in abnormal target organ innervation (Jain et al., 2004). We therefore examined whether TH-positive fiber density in the striatum and the NAc in $\operatorname{Ret}^{\text {RETfloxEGFP/- }}$ :Dat ${ }^{\text {Cre/+ }}$ mice was abnormal. Results show no significant difference in TH-positive nerve fibers in Ret $^{\text {RETfloxEGFP/- }}:$ Dat ${ }^{\text {Cre/+ }}$ mice compared with controls (Fig. 4C). These extensive morphometric analyses in $\operatorname{Ret}^{\text {RETfloxEGFP/- }}$ : $\mathrm{Dat}^{\mathrm{Cre} /+}$ mice suggested that the nigrostriatal and the VTA-accumbens pathways were intact despite losing RET in the vast 
A
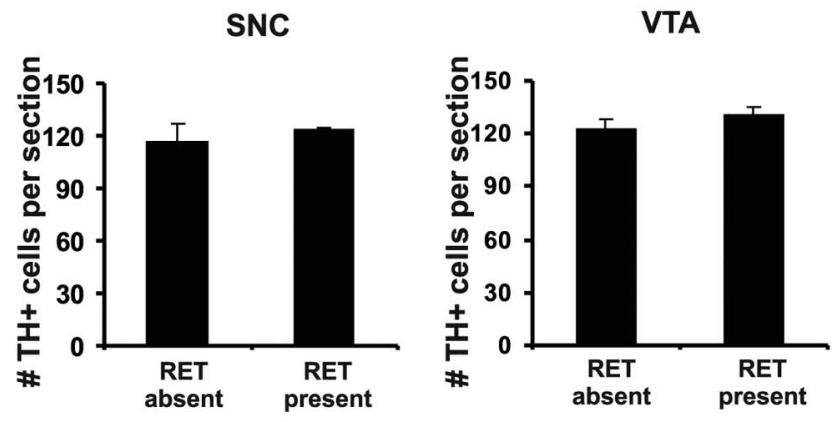

B

SNC

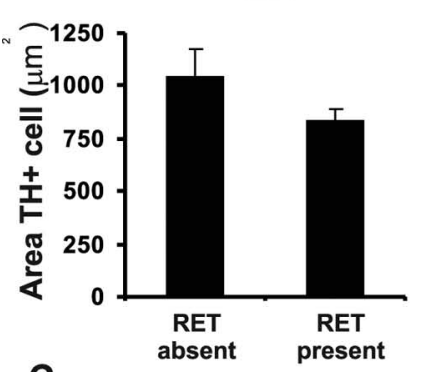

C
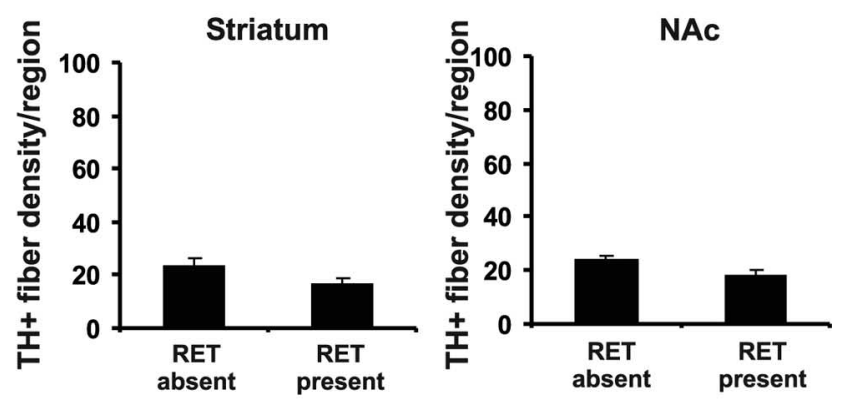

D

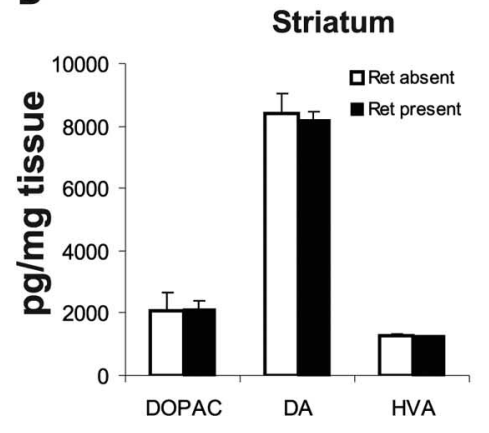

Figure 4. Morphometric and biochemical analysis of dopaminergic neurons in adult Ret ${ }^{R E T}$. floxEGFP/-:Dat ${ }^{\text {(re/+ }}$ mice. A-C, Immunohistochemical analyses of TH-positive neuron number per section $(\boldsymbol{A})$, somal area (in square micrometers) per TH-positive neuron $(\boldsymbol{B})$ in the SNC and the VTA, and density of TH-positive nerve fibers $(\boldsymbol{C})$ represented as percentage of fibers overlying a grid (see Materials and Methods) in the striatum and NAc in RET-absent $(n=4)$ and RET-present $(n=4)$ groups (mean \pm SEM; $p>0.05$ ). D, HPLC analysis of dopamine (DA) and its metabolites (DOPAC; HVA) from similar regions of the striatum (see Materials and Methods) show no difference in RET-absent and RET-present groups (mean \pm SEM; $p>0.05 ; n=3$ for each group).

majority of dopaminergic neurons. Decreased striatal dopamine is observed in a number of PD models and reflects the activity of the nigrostriatal pathway. We therefore measured levels of dopamine and its metabolites in the striatum to further assess the impact of RET loss in the SNC on the nigrostriatal pathway. The levels of dopamine and its metabolites (DOPAC and HVA) were the same in $\operatorname{Ret}^{\text {RETfloxEGFP/- }}:$ Dat ${ }^{\text {Cre/+ }}$ mice and control mice, indicating that loss of RET does not alter dopamine levels in the striatum (Fig. 4D).

Sensorimotor behavior analyses of RET conditional mice In the enteric nervous system, reduced RET results in dramatic functional abnormalities despite relatively normal morphology (Gianino et al., 2003). To determine whether mice in which RET is conditionally absent in dopaminergic neurons exhibit sensorimotor impairments despite apparently normal SNC morphology, we performed a battery of sensorimotor tests on adult (6-12 months of age) $\operatorname{Ret}^{\text {RETfloxEGFP/- }}: \mathrm{Dat}^{\mathrm{Cre} /+}(n=7)$ and control mice $(n=10)(6-12$ months of age $)$ with at least one functional RET allele in the $\mathrm{Dat}^{\mathrm{Cre} /{ }^{+}}$background $(n=10)$. It is important to note that, to avoid any unanticipated confounding effects of reduced Dat dosage on behavioral or metabolite levels (Giros et al., 1996), we kept the genetic dosage of Dat equivalent $\left(\mathrm{Dat} \mathrm{Cre/+}^{\mathrm{C}}\right)$ in both the control and experimental groups. An ANOVA on the horizontal activity data (Fig. $5 \mathrm{~A}$ ) yielded a significant main effect of genotype $\left(F_{(1,13)}=8.89 ; p=0.011\right)$, showing that the adult Ret $^{\text {RETfloxEGFP/- }}$ :Dat ${ }^{\text {Cre/+ }}$ (RET absent) mice were modestly but significantly less active than controls (RET present) in terms of total ambulations (whole-body movements) exhibited over the $1 \mathrm{~h}$ test session. There were no significant effects involving gender. Mice lacking RET in the midbrain exhibited normal rearing behavior but traveled less in the periphery of the field and made fewer entries into the center of the field $(179 \pm 34)$ compared with controls $(275 \pm 29)\left(F_{(1,13)}=8.36 ; p=0.013\right)$ (supplemental Fig. 3, available at www.jneurosci.org as supplemental material). Because there were no differences between the two groups with regard to time spent and distance traveled in the center, the difference in center entries probably reflected differences in overall horizontal activity rather than in altered emotionality (e.g., anxiety-like behaviors) by $\operatorname{Ret}^{\text {RETfloxEGFP/- }}$ :Dat ${ }^{\text {Cre/+ }}$ mice.

Analysis of the data from other behavioral tests uniformly showed that the $\operatorname{Ret}^{\text {RETfloxEGFP/- }}:$ Dat ${ }^{\text {Cre } /+}$ mice did not differ from controls on any of the three components of the rotarod test or on any of the seven tests within the sensorimotor battery (Fig. $5 B, C$; supplemental Fig. 3, available at www.jneurosci.org as supplemental material). Results from the constant speed (supplemental Fig. 1, available at www.jneurosci.org as supplemental material) and "accelerating" rotarod (Fig. 5B) measures suggested that the groups did not differ in their abilities to maintain balance while performing a continuous motor coordination task. In addition, the lack of differences between groups on the stationary rod and in the sensorimotor battery suggested that the Ret $^{\text {RETfloxEGFP/- }}:$ Dat ${ }^{\text {Cre/+ }}$ mice did not have impairments in static balance, strength, initiation of movement, or in the speed of movement (e.g., pole test) (Fig. 5C). We chose to show data from the accelerating rotarod and pole tests, because they are representative of the general similarity between RET-absent and RETpresent groups and because they are often used to evaluate motor/sensorimotor impairments in rodent models of PD (Tillerson et al., 2002; Fleming et al., 2004; Iancu et al., 2005). In summary, our behavioral results suggest that the absence of RET in midbrain dopaminergic neurons is associated with modest decrements in locomotor activity, whereas most sensorimotor functions seem to be unaffected. 
A

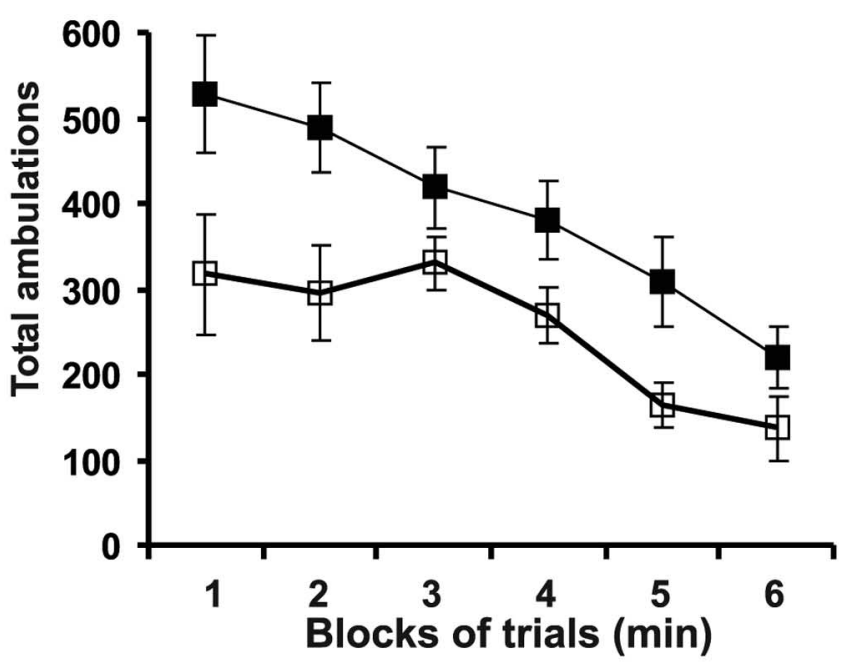

B
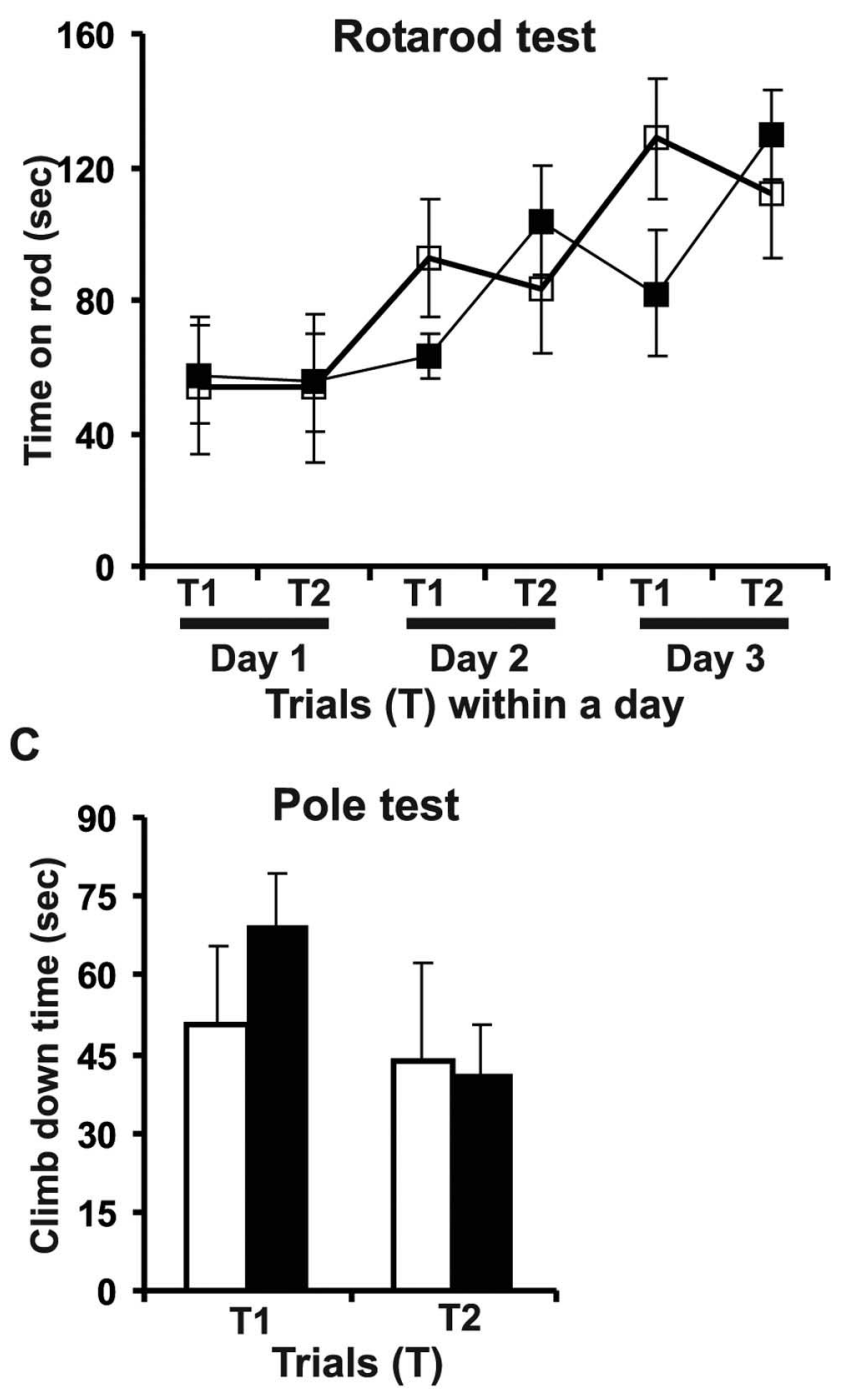

RET absent

RET present

Figure 5. Characterization of sensorimotor behavior in adult Ret $^{\text {RETfloxEGFP/- }}$ :Dat ${ }^{\text {(re/+ }}$ mice. Total ambulations $(\boldsymbol{A})$ were recorded during the $1 \mathrm{~h}$ of locomotor activity/open field behavior test in Ret $^{\text {RETfloxEGFP/- }}$ :Dat ${ }^{\text {(re/+ }}$ mice (RET absent, $n=7$ ) and in control mice with at least one

\section{Discussion}

GDNF-mediated RET signaling is implicated in the function of a variety of PNS and CNS neuronal populations that are central to the pathogenesis of a number of neurodegenerative diseases and drug addiction. Because of neonatal lethality in Ret null mice, the role of this signaling pathway in adulthood, both in normal physiology and in injury, has not been amenable to study. To overcome this hurdle, we report the successful creation and initial characterization of RET conditional mice that will be widely useful to test the importance of GFL-mediated signaling in the pathogenesis of several diseases. Furthermore, our strategy of EGFP reporter activation when RET is deleted provides a powerful way for detecting the cell types in which RET has been excised.

An important finding of our studies is that RET is dispensable for the maintenance and function of the dopaminergic neurons in the SNC and VTA in adult mice. Gene knock-out studies of GFLs and RET indicate that physiologic effects of GFLs are mediated by RET (Airaksinen and Saarma, 2002). GFLs promote the survival of midbrain dopaminergic neurons in a number of models of PD. In animal models with markedly decreased or absent Ret signaling, it has been shown that Ret is not necessary for the embryonic development or the survival of the midbrain dopaminergic neurons perinatally (Airaksinen et al., 1999; Jain et al., 2004). The midbrain dopaminergic neurons undergo two rounds of apoptosis in the first $2-3$ postnatal weeks before attaining their differentiated, defined role in the midbrain (Burke, 2004). Because neurodegenerative disorders such as PD are modeled in adult mice, we generated viable adult mice in which RET is specifically deleted in Ret-expressing dopaminergic neurons including the SNC and the VTA by using dopaminergic specific Cre (Cre expressed by Dat locus) (Zhuang et al., 2005). Our extensive morphological, biochemical, and behavioral analysis demonstrate that RET deletion in both SNC and VTA dopaminergic neurons does not have deleterious effects on these cell types, as assessed by these parameters. Although our data demonstrate that Ret-mediated signaling does not affect the ultimate outcome (i.e., cell number) of the naturally occurring neural death (Burke, 2004), it is certainly possible that the timing of the events was altered in the conditional animals.

There could be several possibilities that could explain the lack of deficits in the midbrain dopaminergic neurons in these conditional animals in which RET has been excised in these neurons. First, RET may not be important in the normal physiology of these neurons, but may have a protective role when these cell types are injured. To date, all protective effects of GDNF, both in vitro and in PD models, have been observed in abnormal physiological situations such as toxic injury or in cell culture, consistent with this idea. Future studies of RET conditional animals in injury models will be needed to examine this possibility. Second, it is possible that the neuroprotective role of RET may not be attributable to its activity directly in the midbrain dopaminergic neurons, but may be mediated by nondopaminergic cells such as microglia in which DatCre is not active (Walker et al., 1998; Honda et al., 1999). If this is the case, then one must consider alternative target cell types for therapy in addiction and PD. A

$\leftarrow$

functional Ret allele (RET present, $n=10$ ). Total ambulations $(\boldsymbol{A})$ are represented in $10 \mathrm{~min}$ bins, and results showed a modest, but significant reduction in horizontal activity in the RETabsent group compared with controls during the $1 \mathrm{~h}$ of testing (mean $\pm \mathrm{SEM} ; p=0.011$ ). The groups did not differ in their abilities to remain on the accelerating rotatod (rotarod test; $\boldsymbol{B}$ ), or with regard to the times required to climb down the pole during the pole test (C). 
third possibility is that the neuroprotective effects of GFLs might be occurring through non-RET-dependent signaling. In this regard, NCAM (neural cell adhesion molecule) has been shown to be a potential alternative means of mediating GDNF signaling; however, its physiological relevance in adult midbrain dopaminergic neurons has not been determined (Paratcha et al., 2003). Finally, it is conceivable that abnormalities in these neuronal populations may be noticeable in aged mice (2-3 years of age), because cell loss in PD occurs slowly over time. Support for this idea also comes from the observation that mice with reduced levels of the receptors for BDNF (another neurotrophic factor shown to enhance dopaminergic neuron survival) have normal SNC neurons in adulthood (6-8 months) but show a $20-30 \%$ decrease in morphometric studies in aged mice (21-23 months) (von Bohlen und Halbach et al., 2005). Our present study was aimed at successful generation of RET conditional mice and determining its physiological role in maintenance of dopaminergic neurons during the first year of life. Long-term studies will be needed to determine whether RET is required for SNC and VTA function in aged mice.

Given the role of dopamine in movement disorders, our initial behavioral studies focused on the effects of RET deletion on several motor/sensorimotor functions. The results of our behavioral tests showed that $\operatorname{Ret}^{\text {RETfloxEGFP/- }}:$ Dat ${ }^{\text {Cre } /+}$ mice differed from control mice only in terms of locomotor activity in which Ret $^{\text {RETfloxEGFP/- }}$ :Dat ${ }^{\text {Cre/+ }}$ mice were found to be modestly hypoactive. This is consistent with results from other mouse models of PD involving MPTP (1-methyl-4-phenyl-1,2,3,6-tetrahydropyridine) treatment (Sedelis et al., 2000; Leng et al., 2004) in which locomotor activity has been found, at least initially, to be reduced, although levels may return to normal or even become reversed over time (Leng et al., 2004). Locomotor activity, pole, and rotarod tests are often-used measures for evaluating motor/ sensorimotor deficits in rodent models of PD. However, the results of the pole and rotarod tests did not provide evidence for a PD-like phenotype in $\operatorname{Ret}^{\text {RETfloxEGFP/- }}:$ Dat ${ }^{\mathrm{Cre} /+}$ mice, nor did it appear that these mice had any sensorimotor impairments. Although it is possible that test sensitivity could be an issue concerning the lack of differences between groups, we do not think that is likely. Although it is true that certain rotarod protocols have been found to be useful for demonstrating dopaminerelated sensorimotor deficits in some (Petroske et al., 2001; Baquet et al., 2005; Iancu et al., 2005) but not all (Tillerson et al., 2002; Fleming et al., 2004) mouse models of PD, the pole test has been recently touted as being a highly sensitive test for detecting subtle sensorimotor deficits in mice overexpressing wild-type human $\alpha$-synuclein (Fleming et al., 2004). The results of the pole test did not reveal any differences between $\operatorname{Ret}^{\text {RETfloxEGFP/- }}$ : $\mathrm{Dat}^{\mathrm{Cre} /+}$ and control mice. It has been our experience in several studies that mutant mice that exhibit performance deficits on the rotarod also show impairment on several other sensorimotor tests, which suggests to us that the lack of differences between groups in the present study is not attributable to dampened test sensitivity. The mechanism for reduced activity in $\operatorname{Ret}^{\text {RETfloxEGFP/+ }}$ : $\mathrm{Dat}^{\mathrm{Cre} /+}$ mice is not clear. We believe it is unlikely to represent a PD-like phenotype because all other tests of sensorimotor function and all morphological and biochemical indices showed no effects of RET deletion (in PD models, typically 30-50\% loss of SNC neurons occurs before manifestation of SNC-related behavior abnormalities). Alternatively, hypoactivity in these animals could also indicate a preparkinsonian phenotype or be attributable to differences in activities or levels of human and mouse Ret in nondopaminergic cells.
In summary, absence of significant pathology because of RET deletion in the SNC and VTA provides evidence in vivo for the first time that RET is not critical for providing trophic support to these neurons in adult mice. The RET conditional mice, and mice with expression of EGFP reporter from Ret locus provide critical tools to study postnatal RET function, and to ascertain whether RET signaling pathways are involved in transducing GFL survival signals in the midbrain dopaminergic system during injury or addiction.

\section{References}

Airaksinen MS, Saarma M (2002) The GDNF family: signalling, biological functions and therapeutic value. Nat Rev Neurosci 3:383-394.

Airaksinen MS, Titievsky A, Saarma M (1999) GDNF family neurotrophic factor signaling: four masters, one servant? Mol Cell Neurosci 13:313-325.

Baloh RH, Enomoto H, Johnson Jr EM, Milbrandt J (2000) The GDNF family ligands and receptors_-implications for neural development. Curr Opin Neurobiol 10:103-110.

Baquet ZC, Bickford PC, Jones KR (2005) Brain-derived neurotrophic factor is required for the establishment of the proper number of dopaminergic neurons in the substantia nigra pars compacta. J Neurosci 25:6251-6259.

Burke RE (2004) Ontogenic cell death in the nigrostriatal system. Cell Tissue Res 318:63-72.

Cheng FC, Ni DR, Wu MC, Kuo JS, Chia LG (1998) Glial cell line-derived neurotrophic factor protects against 1-methyl-4-phenyl-1,2,3,6tetrahydropyridine (MPTP)-induced neurotoxicity in C57BL/6 mice. Neurosci Lett 252:87-90.

Date I, Aoi M, Tomita S, Collins F, Ohmoto T (1998) GDNF administration induces recovery of the nigrostriatal dopaminergic system both in young and aged parkinsonian mice. NeuroReport 9:2365-2369.

Enomoto H, Crawford PA, Gorodinsky A, Heuckeroth RO, Johnson Jr EM, Milbrandt J (2001) RET signaling is essential for migration, axonal growth and axon guidance of developing sympathetic neurons. Development 128:3963-3974.

Fleming SM, Salcedo J, Fernagut PO, Rockenstein E, Masliah E, Levine MS, Chesselet MF (2004) Early and progressive sensorimotor anomalies in mice overexpressing wild-type human $\alpha$-synuclein. J Neurosci 24:9434-9440.

Franklin K, Paxinos G (1997) The mouse brain in stereotaxic coordinates. New York: Academic.

Gash DM, Zhang Z, Ovadia A, Cass WA, Yi A, Simmerman L, Russell D, Martin D, Lapchak PA, Collins F, Hoffer BJ, Gerhardt GA (1996) Functional recovery in parkinsonian monkeys treated with GDNF. Nature 380:252-255.

Gianino S, Grider JR, Cresswell J, Enomoto H, Heuckeroth RO (2003) GDNF availability determines enteric neuron number by controlling precursor proliferation. Development 130:2187-2198.

Gill SS, Patel NK, Hotton GR, O’Sullivan K, McCarter R, Bunnage M, Brooks DJ, Svendsen CN, Heywood P (2003) Direct brain infusion of glial cell line-derived neurotrophic factor in Parkinson disease. Nat Med 9:589-595

Giros B, Jaber M, Jones SR, Wightman RM, Caron MG (1996) Hyperlocomotion and indifference to cocaine and amphetamine in mice lacking the dopamine transporter. Nature 379:606-612.

Grady RM, Wozniak DF, Ohlemiller KK, Sanes JR (2006) Cerebellar synaptic defects and abnormal motor behavior in mice lacking $\alpha$ - and $\beta$-dystrobrevin. J Neurosci 26:2841-2851.

Green-Sadan T, Kinor N, Roth-Deri I, Geffen-Aricha R, Schindler CJ, Yadid G (2003) Transplantation of glial cell line-derived neurotrophic factorexpressing cells into the striatum and nucleus accumbens attenuates acquisition of cocaine self-administration in rats. Eur $\mathrm{J}$ Neurosci 18:2093-2098.

Green-Sadan T, Kuttner Y, Lublin-Tennenbaum T, Kinor N, Boguslavsky Y, Margel S, Yadid G (2005) Glial cell line-derived neurotrophic factorconjugated nanoparticles suppress acquisition of cocaine selfadministration in rats. Exp Neurol 194:97-105.

Griffey MA, Wozniak D, Wong M, Bible E, Johnson K, Rothman SM, Wentz AE, Cooper JD, Sands MS (2006) CNS-directed AAV2-mediated gene 
therapy ameliorates functional deficits in a murine model of infantile neuronal ceroid lipofuscinosis. Mol Ther 13:538-547.

Gundersen HJ, Bendtsen TF, Korbo L, Marcussen N, Moller A, Nielsen K, Nyengaard JR, Pakkenberg B, Sorensen FB, Vesterby A, West MJ (1988a) Some new, simple and efficient stereological methods and their use in pathological research and diagnosis. APMIS 96:379-394.

Gundersen HJ, Bagger P, Bendtsen TF, Evans SM, Korbo L, Marcussen N, Moller A, Nielsen K, Nyengaard JR, Pakkenberg B, Sorensen FB, Vesterby A, West MJ (1988b) The new stereological tools: disector, fractionator, nucleator and point sampled intercepts and their use in pathological research and diagnosis. APMIS 96:857-881.

He DY, McGough NN, Ravindranathan A, Jeanblanc J, Logrip ML, Phamluong K, Janak PH, Ron D (2005) Glial cell line-derived neurotrophic factor mediates the desirable actions of the anti-addiction drug ibogaine against alcohol consumption. J Neurosci 25:619-628.

Honda S, Nakajima K, Nakamura Y, Imai Y, Kohsaka S (1999) Rat primary cultured microglia express glial cell line-derived neurotrophic factor receptors. Neurosci Lett 275:203-206.

Horger BA, Nishimura MC, Armanini MP, Wang LC, Poulsen KT, Rosenblad C, Kirik D, Moffat B, Simmons L, Johnson Jr E, Milbrandt J, Rosenthal A, Bjorklund A, Vandlen RA, Hynes MA, Phillips HS (1998) Neurturin exerts potent actions on survival and function of midbrain dopaminergic neurons. J Neurosci 18:4929-4937.

Iancu R, Mohapel P, Brundin P, Paul G (2005) Behavioral characterization of a unilateral 6-OHDA-lesion model of Parkinson's disease in mice. Behav Brain Res 162:1-10.

Jain S, Naughton CK, Yang M, Strickland A, Vij K, Encinas M, Golden J, Gupta A, Heuckeroth R, Johnson Jr EM, Milbrandt J (2004) Mice expressing a dominant-negative Ret mutation phenocopy human Hirschsprung disease and delineate a direct role of Ret in spermatogenesis. Development 131:5503-5513.

Jain S, Encinas M, Johnson Jr EM, Milbrandt J (2006) Critical and distinct roles for key RET tyrosine docking sites in renal development. Genes Dev 20:321-333.

Jakobsen B, Gramsbergen JB, Moller Dall A, Rosenblad C, Zimmer J (2005) Characterization of organotypic ventral mesencephalic cultures from embryonic mice and protection against MPP toxicity by GDNF. Eur J Neurosci 21:2939-2948.

Koob GF, Sanna PP, Bloom FE (1998) Neuroscience of addiction. Neuron 21:467-476.

Kordower JH, Emborg ME, Bloch J, Ma SY, Chu Y, Leventhal L, McBride J, Chen EY, Palfi S, Roitberg BZ, Brown WD, Holden JE, Pyzalski R, Taylor MD, Carvey P, Ling Z, Trono D, Hantraye P, Deglon N, Aebischer P (2000) Neurodegeneration prevented by lentiviral vector delivery of GDNF in primate models of Parkinson's disease. Science 290:767-773.

Leng A, Yee BK, Feldon J, Ferger B (2004) Acoustic startle response, prepulse inhibition, and spontaneous locomotor activity in MPTP-treated mice. Behav Brain Res 154:449-456.

Messer CJ, Eisch AJ, Carlezon Jr WA, Whisler K, Shen L, Wolf DH, Westphal H, Collins F, Russell DS, Nestler EJ (2000) Role for GDNF in biochemical and behavioral adaptations to drugs of abuse. Neuron 26:247-257.

Meyers EN, Lewandoski M, Martin GR (1998) An Fgf8 mutant allelic series generated by Cre- and Flp-mediated recombination. Nat Genet 18:136-141.

Naughton CK, Jain S, Strickland AM, Gupta A, Milbrandt J (2006) Glial cell-line derived neurotrophic factor-mediated RET signaling regulates spermatogonial stem cell fate. Biol Reprod 74:314-321.

Paratcha G, Ledda F, Ibanez CF (2003) The neural cell adhesion molecule NCAM is an alternative signaling receptor for GDNF family ligands. Cell 113:867-879.

Pehek EA, Crock R, Yamamoto BK (1992) Selective subregional dopamine depletions in the rat caudate-putamen following nigrostriatal lesions. Synapse 10:317-325.

Petroske E, Meredith GE, Callen S, Totterdell S, Lau YS (2001) Mouse model of Parkinsonism: a comparison between subacute MPTP and chronic MPTP/probenecid treatment. Neuroscience 106:589-601.

Schuchardt A, D'Agati V, Larsson-Blomberg L, Costantini F, Pachnis V (1994) Defects in the kidney and enteric nervous system of mice lacking the tyrosine kinase receptor Ret. Nature 367:380-383.

Schuchardt A, D’Agati V, Pachnis V, Costantini F (1996) Renal agenesis and hypodysplasia in ret-k- mutant mice result from defects in ureteric bud development. Development 122:1919-1929.

Sedelis M, Hofele K, Auburger GW, Morgan S, Huston JP, Schwarting RK (2000) MPTP susceptibility in the mouse: behavioral, neurochemical, and histological analysis of gender and strain differences. Behav Genet 30:171-182.

Slevin JT, Gerhardt GA, Smith CD, Gash DM, Kryscio R, Young B (2005) Improvement of bilateral motor functions in patients with Parkinson disease through the unilateral intraputaminal infusion of glial cell linederived neurotrophic factor. J Neurosurg 102:216-222.

Sun ZH, Lai YL, Li P, Zuo HC, Xie ZP (2004) GDNF augments survival and differentiation of TH-positive neurons in neural progenitor cells. Cell Biol Int 28:323-325.

Tillerson JL, Cohen AD, Caudle WM, Zigmond MJ, Schallert T, Miller GW (2002) Forced nonuse in unilateral parkinsonian rats exacerbates injury. J Neurosci 22:6790-6799.

Tomac AC, Grinberg A, Huang SP, Nosrat C, Wang Y, Borlongan C, Lin SZ, Chiang YH, Olson L, Westphal H, Hoffer BJ (2000) Glial cell linederived neurotrophic factor receptor alpha 1 availability regulates glial cell line-derived neurotrophic factor signaling: evidence from mice carrying one or two mutated alleles. Neuroscience 95:1011-1023.

von Bohlen und Halbach O, Minichiello L, Unsicker K (2005) Haploinsufficiency for trkB and trkC receptors induces cell loss and accumulation of and alpha-synuclein in the substantia nigra. FASEB J 19:1740-1742.

Walker DG, Beach TG, Xu R, Lile J, Beck KD, McGeer EG, L. McGeer P (1998) Expression of the proto-oncogene Ret, a component of the GDNF receptor complex, persists in human substantia nigra neurons in Parkinson's disease. Brain Res 792:207-217.

Wang Q, Bardgett ME, Wong M, Wozniak DF, Lou J, McNeil BD, Chen C, Nardi A, Reid DC, Yamada K, Ornitz DM (2002) Ataxia and paroxysmal dyskinesia in mice lacking axonally transported FGF14. Neuron 35:25-38.

Wozniak DF, Hartman RE, Boyle MP, Vogt SK, Brooks AR, Tenkova T, Young C, Olney JW, Muglia LJ (2004) Apoptotic neurodegeneration induced by ethanol in neonatal mice is associated with profound learning/ memory deficits in juveniles followed by progressive functional recovery in adults. Neurobiol Dis 17:403-414.

Zhuang X, Masson J, Gingrich JA, Rayport S, Hen R (2005) Targeted gene expression in dopamine and serotonin neurons of the mouse brain. J Neurosci Methods 143:27-32. 